\title{
Recurrent Pneumonia-H Type Tracheoesophageal Fistula, Diagnostic Dilemma
}

\author{
Adhikari $\mathbf{S}^{1}$, Malla $\mathrm{K}^{2}$, Poudyal $\mathrm{P}^{3}$
}

\begin{abstract}
Tracheoesophageal fistula (TEF) without associated oesophageal atresia (EA) is a rare congenital anomaly. Most of the children are treated for episodes of pneumonia prior to definitive diagnosis. A five months infant presented with recurrent pneumonia and diagnosis of $\mathrm{H}$ type TEF was made with contrast oesophagogram.
\end{abstract}

\section{Introduction}

$\mathrm{P}$ neumonia is common cause of childhood mortality and morbidity. During childhood recurrent episode of pneumonia need to be evaluated for predisposing factors. Underlying causes are recurrent aspiration, lung disease (airway stenosis, bronchiectasis and middle lobe syndrome or tracheooesophageal fistula) and immune deficiency. In significant number of children no cause may be identified even after extensive diagnostic work-up ${ }^{1}$. H-type TEF is one of rare predisposing factor for recurrent respiratory infections and accounts for $4 \%$ of all congenital tracheoesophageal malformations ${ }^{2}$. The clinical features are variable; common being the recurrent respiratory symptoms, aspiration during feeding with cyanosis, abdominal distension. These episodes are treated as recurrent pneumonia with intravenous antibiotics ${ }^{3,4}$. The symptoms are usually present since birth, but the diagnosis is often delayed and requires high index of suspicion.

\section{The Case}

A five months male child presented to Manipal College of Medical Science and Teaching Hospital with symptoms of cough and fever for three days. Baby was born through normal vaginal delivery in Western Regional Hospital Pokhara, weighing $3.05 \mathrm{~kg}$ with good APGAR scores. From the second day of life baby was treated for pneumonia with intravenous antibiotics for 10 days. Baby was treated for similar respiratory infections at 21 days, 45 days and 4 months. The anthropometric parameters and systemic examination were essentially unremarkable. Complete blood count, coagulation profiles and blood chemistry were in normal range. Chest X-ray showed pneumonitis (Fig.1) Ultrasound abdomen, electrocardiogram and echocardiogram were unremarkable. With history of choking during feed tracheaeosophageal fistula was suspected. A tube oesophagogram was performed which showed contrast flowing into tracheobronchial tree through a fistula
'Dr. Sudhir Adhikari, MBBS, MD, Assistant Professor, ${ }^{2}$ Dr. Kalpana Malla, MBBS, MD, Professor, ${ }^{3}$ Dr. Prithuja Poudyal, MBBS, MD Resident. All from the department of paediatrics, Manipal College of Medical Sciences, Fulbari-11, Pokhara, Nepal.

\section{Address for correspondence}

Dr. Sudhir Adhikari

E-mail: sudhiradhikari99@yahoo.com

\section{How to cite}

Adhikari S, Malla K, Poudyal P. Recurrent Pneumonia-H Type Tracheoesophageal Fistula, Diagnostic Dilemma. J Nepal Paediatr Soc 2014;34(1):71-73.

doi: http://dx.doi.org/10.3126/jnps.v34i1.8517

This work is licensed under a Creative Commons Attribution 3.0 License.

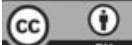

between trachea and esophagus at the level of T2- T3 (Fig.2). Repeat contrast study and bronchoscopy with catheter placement was planned prior to definitive surgery. Patient did not turn up for follow up and operative findings couldn't be confirmed. 


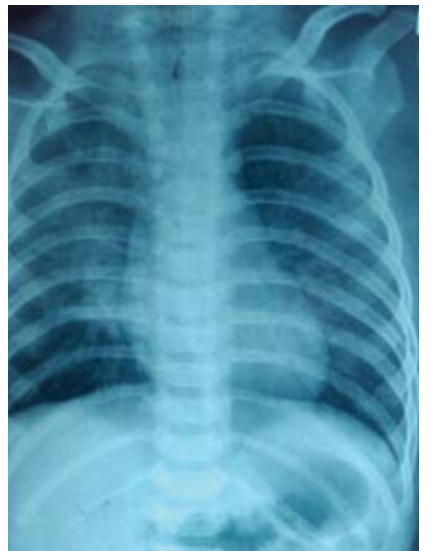

Fig 1: Pneumonitis right middle lobe and upper lobe

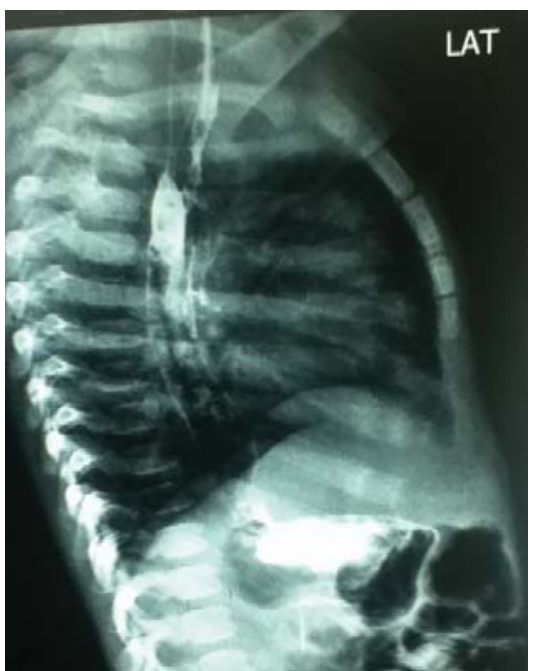

Fig 2: Contrast oesophagogram showing a contrast within the tracheobronchial tree suggestive of TEF

\section{Discussion}

Recurrent episode of respiratory infections are one of the common causes of hospitalization in early childhood. Most of these episodes are treated with intravenous antibiotics and further investigations for underlying etiology is not routinely available in poor resource areas. Most infants with TEF have proximal esophageal atresia with distal TEF. Diagnosis is made soon after birth with apparent clinical features, nevertheless $\mathrm{H}$-type TEF are not diagnosed early because esophagus is patent. The triad of choking and coughing precipitated by feeds, recurrent chest infections, and episodes of abdominal distension was described in five cases from Lady's Hospital for Sick Children and St. Joseph's Hospital, Dublin, between 1971 and $1974^{4}$. In most of the cases infants are treated for respiratory infections. Diagnosis may be delayed from months to years ${ }^{5}$.
Even if treating physician suspects $\mathrm{H}$-type TEF, establishment of diagnosis in developing countries is difficult due to lack of investigations. Many diagnostic methodshavebeenadvocatedforthediagnosis of H-type fistula. Oesophagogram is usually a reliable method to identify congenital H-type tracheoesophageal fistula, though often difficult, requiring multiple attempts before the defect is confirmed. Contrastenhanced studies have the potential risk of aspiration pneumonia and pulmonary injury. Contrast studies can be performed with adequate arrangements for the emergency resuscitation. Three-dimensional computed tomography and virtual bronchoscopy may be useful techniques in pre-operative evaluation ${ }^{6}$. Endoscopic methods like bronchoscopy and oesophagoscopy have the advantage of being diagnostic allowing placement of a catheter across the fistula to assist in its localization during surgery ${ }^{7}$.

Fifty percent of infants with esophageal atresia are nonsyndromic without other anomalies, and the rest have associated anomalies, most often associated with the VATER or VACTERL (vertebral, anorectal, [cardiac], tracheal, esophageal, renal, radial, [limb]) syndrome ${ }^{2}$. Other associated anomalies includes CHARGE syndrome (coloboma of the eye, central nervous system anomalies; heart defects; atresia of the choanae; retardation of growth and/or development; genital and/or urinary defects hypogonadism, Goldenhar's syndrome, esophageal stenosis and syndactyly ${ }^{2,8}$. Congenital malformations are less common in H-type TEF compared to other varieties of esophageal atresia, ${ }^{9}$. None of these associations were found in the index case.

Different surgical approaches have been described for this anomaly. For proximally located fistula the approach of choice is cervicotomy and in cases of distal fistula thoracotomy is usually preferred. Brookes et al reported seven patients of H-type TEF and one patient with a missed proximal $\mathrm{H}$-type fistula associated with esophageal atresia ${ }^{5}$. They presented with coughing while feeding, recurrent pneumonia, and episodic cyanosis. A delay in diagnosis was seen in four patients and ranged from 2.5 months to 5.9 years. In all patients, the diagnosis was made on oesophagogram. The level of the fistulae was between $\mathrm{C} 5$ and $\mathrm{T} 3$, and all were successfully repaired via a right cervical approach. Biechlin et al reported a series of 8 cases of $\mathrm{H}$-type TEF, all were repaired through right cervicotomy ${ }^{10}$. An alternative thoracoscopic approach in a newborn has recently been reported by Allal et $\mathrm{al}^{11}$. Surgery consists of ligation and division of the fistula and repair of the tracheal and esophageal walls. Most 
of children without associated congenital anomalies have good outcome with advancement in diagnostic and therapeutic techniques.

\section{Conclusion}

Though H-type of teacheoesophageal fistula is a rare congenital anomaly, it should be considered as one of the differential diagnosis for recurrent pneumonia in infants and children.

\section{References}

1. Hoving MF, Brand PL. Causes of recurrent pneumonia in children in a general hospital. $J$ Paediatr Child Health 2013;49(3):208-12.

2. Khan S,Orenstein SR Esophageal Atresia and Tracheoesophageal Fistula In: Kliegman RM, Stanton BF, St.gem JW, eds. Nelson Textbook of Pediatrics. $19^{\text {th }}$ ed. 2012. Philadelphia PA: W.B. Saunders; 2088

3. LaSalle AJ, Andrassy RJ, Ver Steeg K, Ratner I. Congenital tracheoesophageal fistula without esophageal atresia. J Thorac Cardiovasc Surg 1979;78(4):583-8.

4. Sundar B, Guiney E J and O'Donnell B. Congenital H-type tracheo-oesophageal fistula. Arch Dis Childhood 1975:50:862.
5. Brookes JT, Smith MC, Smith RJ, Bauman NM, Manaligod JM, Sandler AD H-type congenital tracheoesophageal fistula: University of lowa experience 1985 to 2005. Ann Otol Rhinol Laryngol 2007;116(5):363-8.

6. Le SD, Lam WW, Tam PK, Cheng W, Chan FL. H-type tracheo-oesophageal fistula: appearance on threedimensional computed tomography and virtual bronchoscopy. Pediatr Surg Int 2001;17(8):642-3.

7. Karnak I, Senocak ME, Hiçsonmez A, Buyukpamukçu N.The diagnosis and treatment of H-type tracheoesophageal fistula. J Pediatr Surg 1997;32(12):1670-4.

8. Chittmittrapap S, Spitz L, Kiely EM, Brereton RJ. Oesophageal atresia and associated anomalies. Arch Dis Child 1989;64:364-8.

9. Genty E, Attal P, Nicollas R, Roger G, Triglia JM, Garabe-dian EN, Bobin S. Congenital tracheoesophageal fistula without esophageal atresia. Int J Pediatr Otorhinolaryngol 1999;48: 231-8.

10. Biechlin A, Delattre A, Fayoux P. Isolated congenital tra-cheoesophageal fistula. Retrospective analysis of 8 cases and review of the literature. Rev Laryngol Otol Rhinol 2008;129:147-52.

11. Allal H, Montes-Tapia F, Andina G. Thoracoscopic repair of $\mathrm{H}$-type tracheoesophageal fistula in the newborn: a technical case report. J Pediatr Surg 2004;39:1568-70. 